\title{
El Códice Cardona: un acercamiento a la materialidad y contenido de un documento desconocido
}

Codex Cardona: an approach to the materiality and content of an unknown manuscript

\author{
Javier Eduardo Ramirez López \\ El Colegio de México, México \\ jeramirez@colmex.mx \\ (iD) https://orcid.org/0000-0003-0777-2989
}

\section{Resumen:}

\begin{abstract}
El presente trabajo reúne una serie de propuestas sobre la estructura y contenido de una sección del denominado Códice Cardona basado en algunas imágenes digitales de este de la década de 1980; para lo cual se centra en el análisis de tres páginas de la "Relación del señorío de Xochimilco y la república de indios de Chalco" que está ambientada en la década de 1550. Como es bien sabido, de dicha relación no se conoce su original del siglo XVI, por eso mismo llama la atención el contenido e información plasmado en el Códice Cardona. Aunado a esto, el texto del Cardona mantiene paralelismos con otros documentos de la época lo que permite suponer que es una copia y/o reelaboración de otros documentos históricos.

Palabras clave: Códice Cardona, Chicoloapan, Clasificación de códices, Amate, México.
\end{abstract}

\section{ABSTRACT:}

The present work brings together a series of proposals on the structure and content of a section of the Codex Cardona based on some digital images from the 1980s; for which it focuses on the analysis of three pages of the "Relationship of the Lordship of Xochimilco and the Republic of Indians of Chalco" which is set in the 1550s. As is well known, this relationship is not known in its original of the century XVI, which is why the content and information contained in the Cardona Codex draws attention. In addition to this, the Cardona text maintains parallels with other documents of the time, which allows us to suppose that it is a copy or reworking of other historical documents.

KEYwords: Codex Cardona, Chicoloapan, Classification of codices, Amate, México.

\section{INTRODUCCIÓN}

Este trabajo tiene por objetivo analizar tres páginas que están incluidas en el Códice Cardona y se trata de mostrar qué fuentes pudieron servir de inspiración para su elaboración, lo que ayudará a determinar la posible autenticidad de la información contenida en el documento. Es importante señalar que este texto forma parte de una investigación más amplia y detallada que analiza cerca de 500 páginas del Códice Cardona. Por ello, para el presente artículo se estructuró en dos secciones: la primera, debido a que en esta época se sitúa la elaboración del Códice Cardona, según los estudios del Laboratorio Crocker, está relacionada con la falsificación de códices y documentos en el siglo XX; y la segunda, analiza la información proporcionada sobre el pueblo de San Vicente Chicoloapan plasmada en el Corpus Cardona y la redactada en la "Relación geográfica de Chicoloapan de 1579".

Para tener un contexto actual, es importante mencionar que el Códice Cardona después de tres décadas de misterio volvió aparecer el pasado octubre de 2020 en la Galería Ansorena, de Madrid, cuando se trató de subastar y fue descrito en la sección de "pintura y artes decorativas" del catálogo 405, lote 20. Este anuncio llamó la atención entre los distintos especialistas de temas en mesoamericanos y de algunos medios de comunicación mexicanos, pues es poco lo que se sabe de este documento. Incluso, en el catálogo de la subasta se hizo referencia a que era un códice del siglo XVI. 
Debido a que el Códice Cardona forma parte de una colección particular que por décadas ha permanecido en el anonimato, esto ha dificultado que se pueda realizar un amplio análisis y estudio de su contenido y materialidad. Se debe recordar que el Códice Cardona fue dado a conocer entre distintos especialistas en 1985, cuando por instrucciones del dueño, y mediante un agente, fue ofrecido en venta a la Universidad de Stanford por seis millones de dólares (Bauer, 2009). Para entonces, el Códice Cardona causó el asombro de los especialistas en temas mesoamericanos, porque hasta ese momento nadie sabía nada de la existencia de este documento.

El nombre de este códice se deriva en honor a su autor, el capitán Alonso de Cardona y Villaviciosa; no obstante, lo extraño es que dicha persona no figura en los registros de migrantes europeos en América (Bauer, 2009). Sin embargo, la extrañeza sobre el códice iba más allá, pues estaba constituido por 427 "páginas" de papel indio (amate) con escritura mixta (pictografía y glosas en español). Para esa época, Stephen A. Colston (1985) realizó un informe detallado y un inventario de las imágenes del documento en cuestión, pero, como no pudo tener acceso al códice original, trabajó con 693 "trasparencias" (fotografías) a color. La conclusión que presentó fue que el Códice Cardona estaba dividido en libro 1, 2, 3 y 4, los cuales correspondían a distintas relaciones geográficas del siglo XVI del Valle de México: centro y sur. No obstante, Colston dudaba de la autenticidad del documento porque tenía mapas que parecían una calca de los que se habían realizado en la década de 1570 para las relaciones geográficas. Un caso muy evidente es el del Mapa de Culbuacan de la Relación geográfica de 1579 (véase figura 1) que fue plasmado de manera semejante en el Corpus Cardona (véase figura 2).

FIGURA 1 Y 2

Mapa de Culhuacan. Lado derecho "Relación de Culhuacan, 1579",

Colección Benson de la Universidad de Texas, en Austin; lado izquierdo

"Relación de Iztapalapa, Culhuacan y Mexicalzinco" del Corpus Cardona.

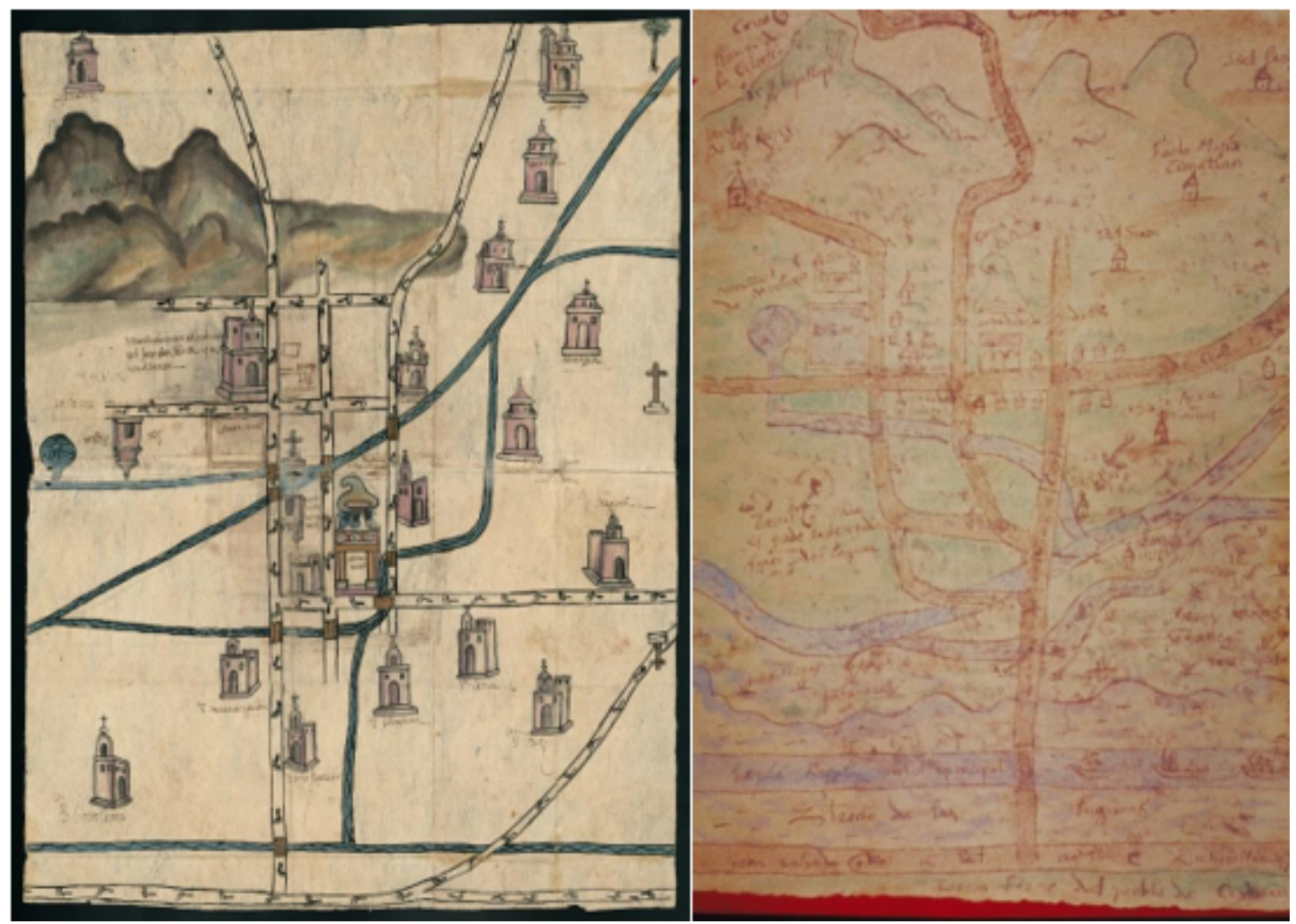

Fuente: imagen en dominio público. 
En ese mismo año, el Códice Cardona fue llevado al Laboratorio Crocker, de la Universidad de California en Davis, donde se le hicieron varias pruebas de pigmentos a los colores empleados en las distintas hojas de amate para que, con base en ello, se pudiera determinar la antiguedad del documento. Para el asombro de todos, los resultados no fueron los esperados. Pues, los estudios mostraron que el códice era de manufactura muy reciente, es decir, del siglo XX. Ello ocasionó que el códice no fuera comprado y se le perdiera la pista por décadas, hasta ahora que se sabe que está en Madrid en espera de un comprador.

La descripción más completa conocida del Códice Cardona es la referida en el catálogo de la casa de subastas de Ansorena, la cual indica que: "está compuesto por 806 páginas (201 bifolios y una página suelta con unas 300 ilustraciones"; ${ }^{1}$ cada bifolio de amate mide 40 por 72 centímetros, el cual a su vez está constituido por cuatro páginas. En este sentido, cada "hoja" o "foja" tiene el tamaño de 40 centímetros de alto por 36 de ancho y está escrita por ambos lados.

Hasta el momento hay un desconocimiento casi total del contenido y la estructura del Códice Cardona. Esto se debe a que, en primer lugar, la obra se fragmentó desde su origen, ya que, en la actualidad distintas personas poseen hojas del códice, pero el corpus más grande del mismo es el que se localiza actualmente en Madrid; y segundo, el actual dueño que posee la mayor cantidad de páginas lo mantiene reservado. En esta sintonía sólo se tiene a las breves descripciones del Códice Cardona por Arnold Bauer (2009) y Stephanie Wood (2010), estos autores tuvieron acceso al códice entre 1985 y 1998. Gracias a sus descripciones se sabe que el Corpus Cardona es un compendio de relaciones geográficas de mediados del siglo XVI del Valle de México. Pero, hasta el momento nadie ha explicado cómo están estructuradas dichas relaciones.

\section{El origen del Corpus Cardona: LA incógnita}

Para este análisis en lugar de referirse al documento como Códice Cardona, se empleará el término Corpus Cardona debido a que la extensión y el contenido permiten postular la idea de que todas las hojas son una compilación de distintas relaciones geográficas del centro y sur del Valle de México. En un artículo próximo a publicar (Ramírez López, 2021), demuestro que el Corpus Cardona está conformado por al menos cinco relaciones geográficas, todas situadas en el siglo XVI: la primera comprendes las parcialidades de Tenochtitlan y Tlatelolco; la segunda refiere a Coyoacan y la zona denominada el Mal País; la tercera es de la región de Iztapalapa, Culhuacan y Mexicalzingo; la cuarta abarca Xochimilco y Chalco; y la última es sobre el cacicazgo de Malacatepec Momoxco (Milpa Alta).

Debido a que el documento fue fechado en el siglo XX por la Universidad de Stanford, es posible considerar al Corpus Cardona como resultado de una reelaboración de fuentes históricas escritas durante la administración de la época de la Monarquía española (1521-1821. Para este preliminar acercamiento al Corpus Cardona se cuenta con varias decenas de fotografías que pertenecieron al arquitecto Guillermo Gutiérrez Esquivel, de las cuales dispongo del permiso del doctor Andrés Reséndez para su publicación y estudio.

Es importante señalar que las imágenes aquí estudiadas estaban en el Códice Cardona que tenía el arquitecto Gutiérrez Esquivel durante las décadas de 1970-1980, pero se desconoce si actualmente aún se encuentran en las hojas que se venden en Ansorena. Esto se debe a que, posiblemente, después de 1985, cuando no fue vendido, el Corpus Cardona regresó a México y se vendió por partes. Sin embargo, no cuento con imágenes de todas las páginas del documento y ello complica la realización de un estudio pormenorizado.

En este sentido, la confección del Corpus Cardona no puede ser un elemento aislado, sino que forma parte de una serie de sucesos históricos y de intereses económicos que se desarrollaron en el siglo XX, ya que en este periodo existieron varios talleres de elaboración de códices, siendo principalmente los de la región de los mayas aquellos que más se falsificaban. Esta forma de elaborar códices fue muy común en el siglo XX, dado que distintas personas se dedicaron a la reelaboración de códices y, gracias a ello, el día de hoy se cuenta con un censo preliminar de 62 piezas (Glass, 1975) y un anexo de 45 obras (Batalla Rosado y González Centeno, 2017). 
Quisiera destacar en este trabajo, a modo de antecedente, el rol del falsificador Genaro López, pues es posible entender que tuvo la misma intención que los autores del Códice Cardona. Es decir, vender una recreación o reconstrucción de un códice, haciéndolo pasar por una pieza de manufactura prehispánica o colonial, según sea el caso, pero empleando materiales que no eran comunes en la época.

Se sabe que López, fue un joven mexicano que estudió en la Academia de San Carlos bajo la dirección del pintor José María Velasco. Fue contratado para realizar una serie de litografías de códices mexicanos que serían exhibidos en la Exposición Histórico-Americana de 1892 en Madrid, con motivo del IV Centenario del descubrimiento de América (Batalla Rosado y González Centeno, 2019).

En esta sintonía, Juan José Batalla Rosado y Gregorio González Centeno (2019) han realizado un análisis detallado de la vida y el censo de las obras del falsificador López. Él poseía una buena habilidad para la elaboración de códices y esto le ayudó para ser elegido como ayudante de dibujo de Francisco del Paso y Troncoso durante su misión en Europa. No obstante, cuando terminó su contrato regresó a México y estuvo elaborando códices en fibra de coco, los que hacía pasar por originales.

La técnica de López era de excelente calidad, pues hasta Alfredo Chavero le compró tres códices y los publicó en 1901 en su obra Pinturas jeroglificas (Glass, 1975). Tiempo después, cuando del Paso y Troncoso recibió el ejemplar del libro de Chavero quedó atónito, pues se trataban de recreaciones de códices con base en imágenes de otros códices que estaban en Europa (Brito Guadarrama, 2006; Meer, 2010). Para los últimos años del siglo XIX y los primeros del siglo XX era difícil que los intelectuales mexicanos tuvieran acceso a los facsimilares de los códices que se publicaban en Europa, pues estos tenían costos elevados y por ello eran fácilmente engañados.

Las obras realizadas por López tenían como base la monumental obra de Lord Kingsborough Antiquities of Mexico, en la cual se editaron varias crónicas y códices desconocidos para esa época (1830-1848). Además, López había consultado y copiado varios códices mexicanos custodiados en distintos acervos europeos, por lo cual sabía la técnica para elaborarlos y es posible que tuviera bocetos en su archivo personal. Esta práctica le sirvió para emprender su taller de falsificación de códices. Pero, tenían algo en particular, el material en que fueron elaborados fue "fibra de coco", un soporte que no se empleó en ningún códice mesoamericano (González Centeno, 2018).

López generalmente utilizó el mencionado soporte como material primario para elaborar sus recreaciones, tal vez como una forma de firmar sus obras, o como un descuido. El éxito del taller fue tal que distintas personas adquirieron estas falsificaciones, pero tenían un patrón recurrente, eran hombres ricos. Un caso peculiar ocurrió a finales del siglo XIX cuando López le vendió al duque de Loubat un códice maya falso y para certificarlo envío una carta en la que explicaba la originalidad del documento. Pasado el tiempo, el duque constató que lo habían timado, así que para darle una lección al falsificador y para desacreditarlo por completo, hizo exhibir el códice maya en un museo neoyorquino y lo acompañó con la carta de López (Batalla Rosado y González Centeno, 2019).

Es posible que para inicios del siglo XX se creara un gran taller de falsificación de antigüedades a cargo de López. A diferencia de otros talleres que "timaban" a los indígenas para que adquirieran títulos primordiales o lienzos de sus tierras; López tenía un mercado diferente, como ya se ha mencionado. En este sentido, se podría aplicar esta suposición a los autores del Corpus Cardona, pues estaban pensando en la elaboración de una obra que tuviera precisamente un mercado diferente. Este era el de las personas que económicamente podían adquirirlo, además de que el material que emplearon era poco común para obras del siglo XVI.

López cometió un descuido al elaborar códices en fibra de coco. En el caso del Corpus Cardona que aquí se analiza y el cual, como ya se mencionó, es un compendio de relaciones geográficas situadas a mediados del siglo XVI, fueron escritas en papel indio (amate), pero ¿por qué no elaborarlas en papel europeo? Es posible que no hayan conseguido la cantidad suficiente de hojas para lo que pensaban realizar, también resulta probable que ocuparan otro soporte para evitar ser delatados por las marcas de agua o filigranas que no correspondieran a la época en que se trataba de situar el corpus. 
Debido a la extensión del Corpus Cardona y a la diversidad de caligrafías, trazos y pinturas, se puede considerar que fue un taller quien lo elaboró. Es decir, es una forma de manufactura en el sentido de que hay varias personas involucradas, posiblemente historiadores, cronistas, antropólogos, pintores y una variedad de escribanos que formaron un circuito erudito. Además, el taller no sólo habría fabricado el Corpus Cardona, sino que es posible que hayan tenido más obras. Un ejemplo de esto es el Códice Quezada, el cual tiene un rasgo distintivo en el uso de la palabra "puebla" en lugar de "pueblo" y de la caligrafía de la "y" (véanse figuras 3 y 4). En este sentido, el Taller Cardona trató de cubrir la mayor cantidad de detalles que pudieran delatar sus obras, fue así como diseñaron el proyecto del Corpus Cardona como algo exótico del siglo XVI. Aun así, hace falta un detallado y reciente análisis por especialistas en tintas y papel para que determinen el tipo y la antigüedad de los pigmentos empleados en dicho trabajo y, de esa manera, se podrá ver si son de origen natural o sintético y con ello determinar su antigüedad. En este tenor, podrán secundar los resultados del Laboratorio Crocker o realizar una nueva propuesta.

FIGURAS 3 Y 4

Caligrafía de la palabra "yndyo" en el Códice Quezada (lado derecho) y de la "Relación de México y Tlatelolco" del Corpus Cardona (lado izquierdo).

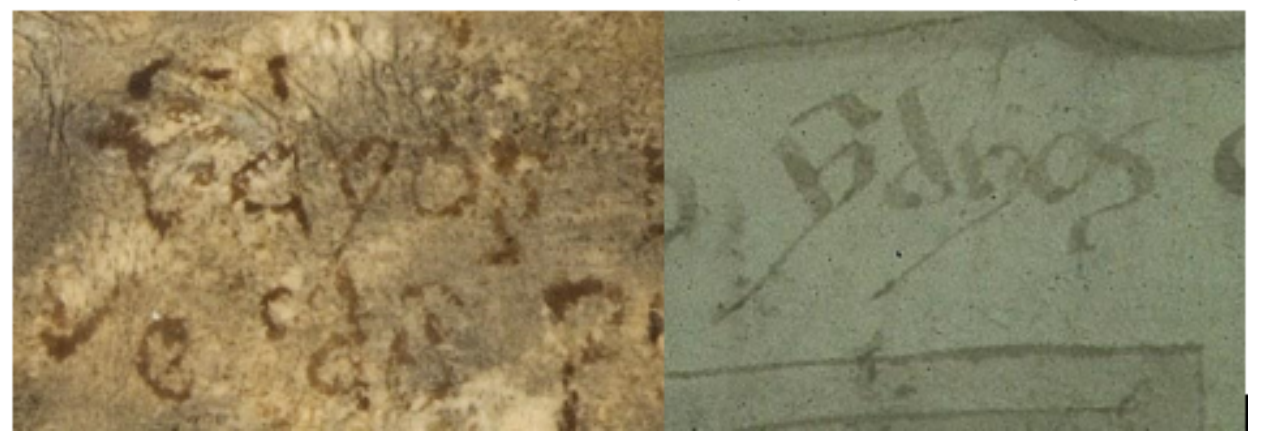

Fuente: reproducción autorizada por la doctora Ana Rita Valero de García Lazcuráin y del doctor Andrés Reséndez.

La omisión de esos detalles, los cuales podrían sospechar de la autenticidad del Corpus Cardona durante su proceso de elaboración permite intuir que los miembros del taller pensaron en los puntos negativos que tendría la confección de un códice. En este sentido, el o los artistas del taller del Corpus Cardona emplearon el amate como algo que visualmente fuese atractivo. Para ello, hay que recordar cuántas falsificaciones de documentos (por ejemplo, testamentos en náhuatl) se realizaron sobre amate. Así, utilizar el amate conlleva pensar en lo antiguo, en lo indio. Puesto que una parte considerable de los códices que se conservan del siglo XVI están elaborados en este soporte material. Esta reflexión, posiblemente, la sabían los miembros del taller y en distintas partes del Corpus Cardona expresaron por qué el uso de ese material para su elaboración.

Por ejemplo, el escribano de la "Relación de México y Tlatelolco", del Corpus Cardona, argumentó en las páginas 8 y 9 el uso del amate y la caligrafía empleada en la elaboración del documento:

[p. 8] Merced. Antes de seguir esta relaçion e de pedir perdón en los q la leyerâ por la sea y xlleca, le tgo q decir q tengo; q âssi a de zer; q es [...] deschargo e de deçirles q a resultas des una mal cayda de caballo q tube ara cinqo años o mas, y dura e tiezameqdo la manddyestra con la q eschrivo; q no se hacerlo con la zurda e anssi mes sale mui desparexa y oschura; y si a' esta se añade el gruesso papel de la tierra q llamâamâtle en q se eschribe por non aver es otro en estas çerranias; algo abra de me perdonar; q tiempo abra q lo agacopyar bien pulido por buen e venga bista y en buen papel de castilla. [p. 9] $\mathrm{A}^{\circ}$ tonssmo se verâ q es unos libros van las sus foxascintadas con listôgruesso a la romana y estas con filo mas fino a la moda castellana; y pido q non se tome estos por descuido e ynorâcia del autor; sino q vuelvo a repetillo, En aqstas tierras a veces non ai si lo q la buena surthe necesita para façer buen libro y escrito; y para ayûtar les foxas q non anden sueltas e se pierdâ se usado lo q a mano ai $[\ldots]$.

En estas líneas, de manera novelesca, el escribano hizo referencia a que se había caído del caballo hace cinco años y se lastimó la mano derecha. Entonces, como no sabía utilizar su mano zurda, le costó escribir la 
información, a lo que se suma el esfuerzo por cargar el pesado papel amate. Este aspecto es curioso porque el autor hace constar que era de gran volumen y justifica el soporte del documento en papel de los indios con la escasez de papel europeo que se podría emplear para su elaboración. Mediante un análisis de la caligrafía se puede constatar que la letra empleada en el Corpus Cardona no corresponde a ninguna registrada en los catálogos, lo que hace suponer que es una invención. En este sentido, la doctora María del Carmen Martínez Martínez, a raíz de una comunicación personal, considera que posiblemente la caligrafía empleada no es de una mano zurda, sino de una diestra por los distintos trazos de las letras.

En esta vertiente, según los análisis del Laboratorio Crocker de la década de 1980, la manufactura del Corpus Cardona es posible fecharla en el siglo XX. Esto no es difícil de concebir, puesto que durante las décadas de 1960 a 1980 fue cuando el arquitecto Guillermo Gutiérrez Esquivel compró los bifolios en La Lagunilla. Se trata de un lugar peculiar de la Ciudad de México, puesto que era y es un sitio donde se puede encontrar casi cualquier tipo de antiguedades, incluso, hasta un retablo barroco si el coleccionista tenía el suficiente dinero. Otra parte del Corpus Cardona se vendía por hojas o bifolios en un mercado de antigüedades en el barrio de Polanco, de otro estatus económico, frecuentado por la gente con mayor poder adquisitivo que podía comprar las hojas sin inconvenientes.

Debido a la temporalidad en que aparecen las hojas a la venta no podían ser copias exactas de un códice ya conocido, es así como el Taller Cardona mantenía un discurso propio. Para esa época, por un lado, John B. Glass (1964) publicó el catálogo de códices que están en el Museo Nacional de Antropología e Historia y ello significó que no podían realizar alguna falsificación de esta colección ya que serían descubiertos con facilidad. Por el otro, la sociedad mexicana de la década de 1970 estaba viviendo varios cambios culturales, donde la identidad prehispánica y algunos aspectos de los indígenas estaban cobrando impulso.

En esta sintonía, los proyectos gubernamentales se caracterizaban por estudiar y editar libros sobre la cosmovisión y lengua de los indígenas muertos, pero sus políticas educativas para los indígenas contemporáneos fueron escasas. A tal grado, que los presidentes José López Portillo (1976-1982) ${ }^{2}$ y Miguel de la Madrid Hurtado (1982-1988) tenían en mente colocar en la plancha del zócalo de la Ciudad de México azulejos que mostraran la primera hoja del Códice Mendocino, la cual trata sobre la fundación de Tenochtitlan.

En este tiempo, y tal vez para satisfacer un mercado más "conservador" de la élite mexicana, se recrearon una serie de códices con aspectos de la vida cotidiana de los indígenas y españoles que vivieron en el Valle de México. Es así como esta pieza pasa a un segundo plano, ya no copian tal cual la información de un códice o documento, pues tratan de modificar las fechas para darle un rasgo de antigüedad.

\section{El Corpus Cardona: de la copia a la recreación de la historia de la cuenca DE MÉXICo}

Si hay dudas sobre el origen y formación del Corpus Cardona, ¿qué tan cierta es la información? Podría postularse en este trabajo que el Corpus Cardona es resultado de la reelaboración de fuentes que ya se conocían desde el siglo XIX, como los códices Mendoza, Aubin, Ramírez, además de las obras de fray Diego Durán y fray Bernardino de Sahagún. Para ello sería necesario realizar un análisis del iconotexto de cada una de las páginas del corpus. También, es posible que el autor o autores intelectuales hayan tenido acceso a los documentos depositados en colecciones privadas, del Archivo General de la Nación, así como de las Relaciones geográficas de los siglo XVI y XVIII.

Además de las fuentes históricas, el autor intelectual debió conocer muy bien la zona sur del Valle de México, ello implica una noción básica de lo que se necesitaba representar; por ejemplo, los sistemas hidráulicos, las técnicas de elaboración de chinampas y los caminos que conectaban a los pueblos; así como sus "jardines o plazas principales". Es posible que los miembros del taller recorrieran las zonas plasmadas en el Corpus Cardona para después poder recrearlas en papel, pues para las décadas de entre 1960 y 1980 aún se conservaba una extensión considerable de chinampas. 
Es sorprendente la cantidad de imágenes que posee el Corpus Cardona y para ser estudiadas se necesitarían análisis propios. Pero, para este caso me centraré en un mapa de Chicoloapan que forma parte del Corpus Cardona y corresponde a la "Relación del señorío de Xochimilco y de la república de indios de Chalco". El análisis de ambas imágenes permite suponer que el localizado en el Corpus Cardona es una copia del mapa de la relación geográfica de 1579 depositada en el Archivo General de Indias.

\subsection{Mapa de la relación del pueblo de Chicoloapan de 1579}

Hasta el momento no hay una metodología de cómo estudiar este tipo de imágenes, pues son recreaciones o copias de otros documentos. No obstante, tal como lo señala Goerges Roque (2012) las obras tienen una argumentación visual, y muestran detalles para llamar la atención. En el caso del Corpus Cardona tiene una argumentación visual en la cual el comprador pudiera centrar su atención en las llamativas imágenes y delicados trazos, por ello se encuentran en el centro; en cambio los textos fueron diseñados para estar en la parte superior e inferior. Es importante señalar que las relaciones geográficas generalmente eran puro texto e incluían un mapa. Pero hay excepciones, como por ejemplo, la relación geográfica de Tezcoco del siglo XVI acompañada de imágenes (Pomar, 1986) y eso mismo pasa con el Manuscrito Glasgow que es la "descripción de la ciudad de Tlaxcala" (Múñoz Camargo, 1981).

El Corpus Cardona está elaborado como un códice de escritura mixta, pero como ya se mencionó hay dudas sobre su autenticidad. En el caso de los códices manufacturados en el siglo XVI, Batalla Rosado (2002a y 2002b) ha propuesto una metodología; la cual consiste en dividir la imagen en dos. La primera es analizar el "libro escrito europeo" (glosas en español, náhuatl o cualquier idioma indígena) y segundo el "libro indígena” (imágenes o pinturas). Esta metodología permitirá un acercamiento al Corpus Cardona para conocer qué fuentes pictográficas y documentales fueron empleadas.

Lo peculiar de la forma de dibujar a las personas es el estilo medieval que le quieren dar y con ello mostrar una antigüedad del siglo XVI, es decir "vemos lo uno en lo otro" (Boehm, 2011). Sin embargo, la forma de trazar los pies y las manos alargadas no se empleó en los códices mesoamericanos. Con respecto a las perspectivas tridimensionales en las construcciones (donde se observa lo alto, largo y ancho), sí era algo común, pues se observa en el Códice Mendoza en una foja donde se plasma su tecpan.

Es así como en la página 162 del Corpus Cardonade la "Relación del señorío de Xochimilco y de la república de indios de Chalco" incluye un mapa con el título "Vera traça puebla de Chicolopã” (véase figura 5), el cual es una copia del mapa titulado "Pueblo de Chicoloapan, de la jurisdicción del corregimiento de Coatepec, y sus inmediaciones” de 1579 que se localiza en el Archivo General de Indias, Sevilla, España (véase figura 6). 


\section{FIGURA 5}

“Mapa de Chicoloapan, 1579”, en Descripción de los pueblos de Coatepec, Chimalhuacán y Chicoloapan, Archivo General de Indias, M-P México, 12.

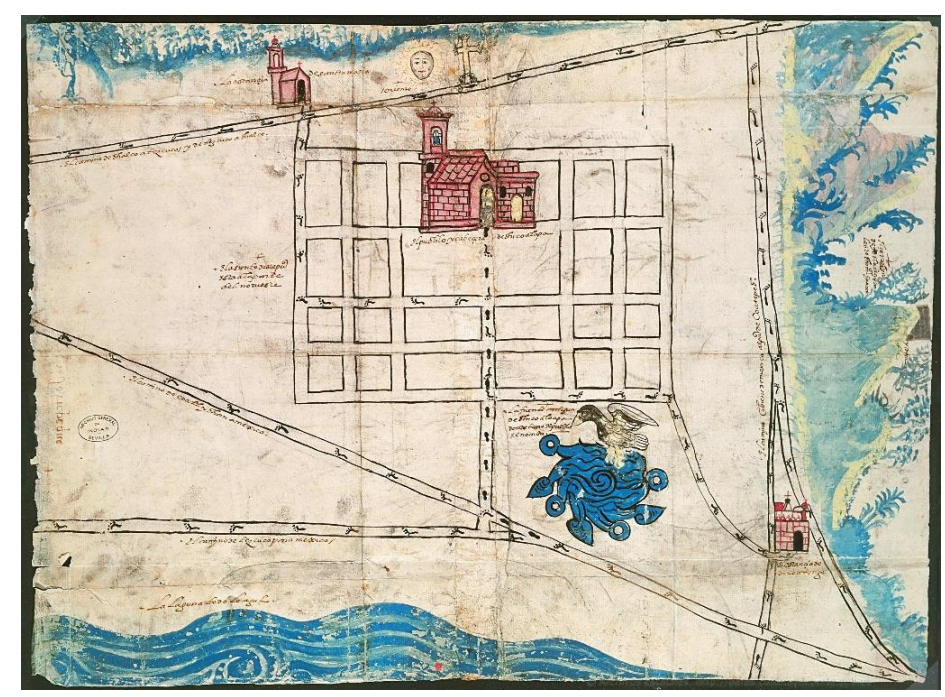

Fuente: imagen en dominio público.

\section{FIGURA 6}

"Vera traça puebla de Chicolopã”, en "Relación de Xochimilco y de la república de indios de Chalco", del Corpus Cardona.

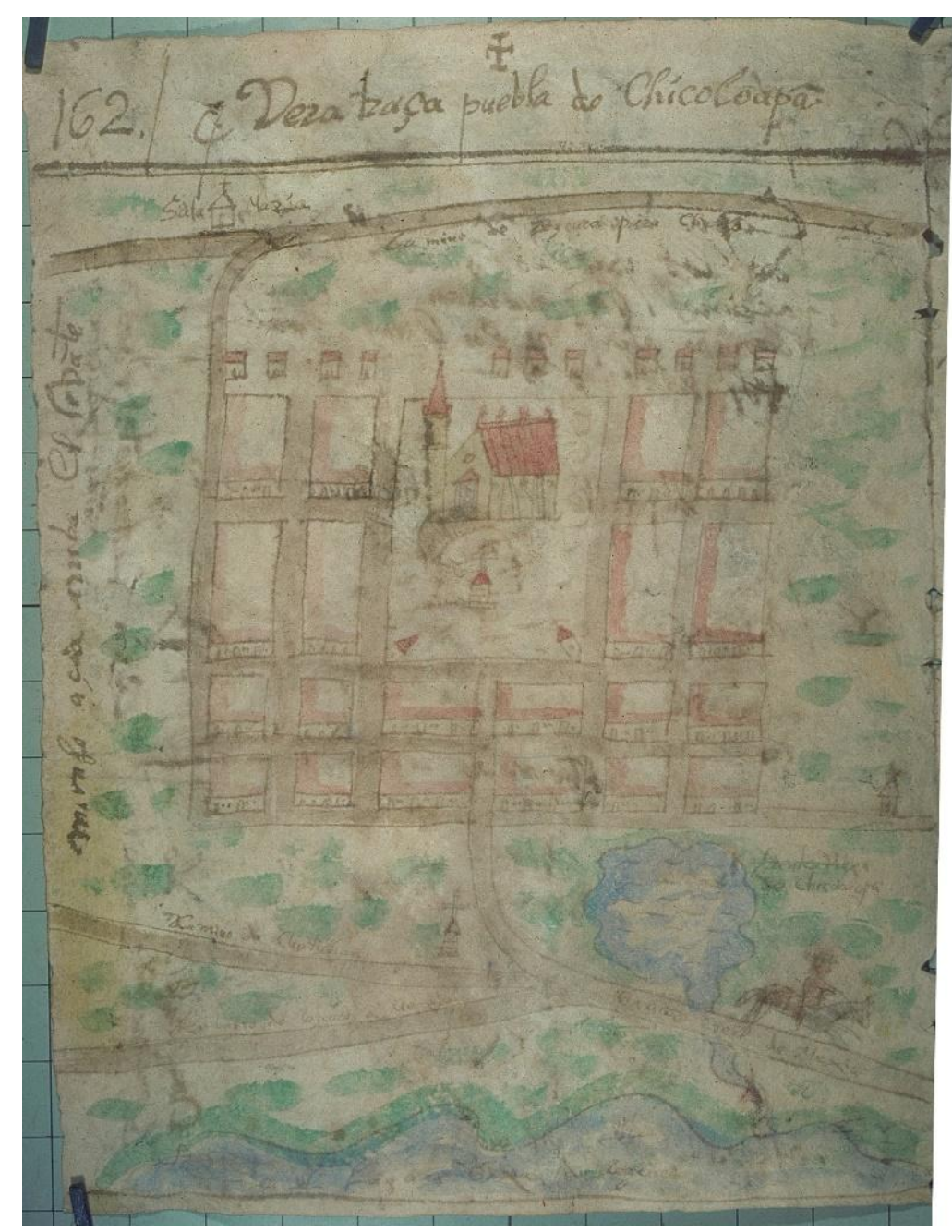

Fuente: reproducción autorizada por el doctor Andrés Reséndez. 
La argumentación que sostiene que la pintura del Corpus Cardona es copia se debe a que en los mapas de los pueblos de indios del siglo XVI que actualmente se conservan, solo hay un caso peculiar donde hay un mismo modelo. Este corresponde al pueblo de San Miguel Coatlinchan, jurisdicción de Tezcoco, cuando los indios pelearon algunas mercedes de tierras en 1579 (Pulido Rull, 2020). En dicho litigio el español que solicitó sus caballerías de tierras mandó a realizar un mapa (véase figura 7), al mismo tiempo los indios que protestaron sobre los límites también elaboraron un mapa, pero sobre amate (véase figura 8). Hasta el momento, no se conoce de otro caso en donde existan dos mapas semejantes o iguales del siglo XVI.

FIGURAS 7 Y 8

Lado derecho, "Mapa de Coatlinchan 1", Archivo General de la Nación de México, Tierras, vol. 2688, exp. 35, f. 373. Lado izquierdo, "Mapa de Coatlinchan 2”, Archivo General de la Nación de México, Tierras, vol. 2688, exp. 3, f. 392.

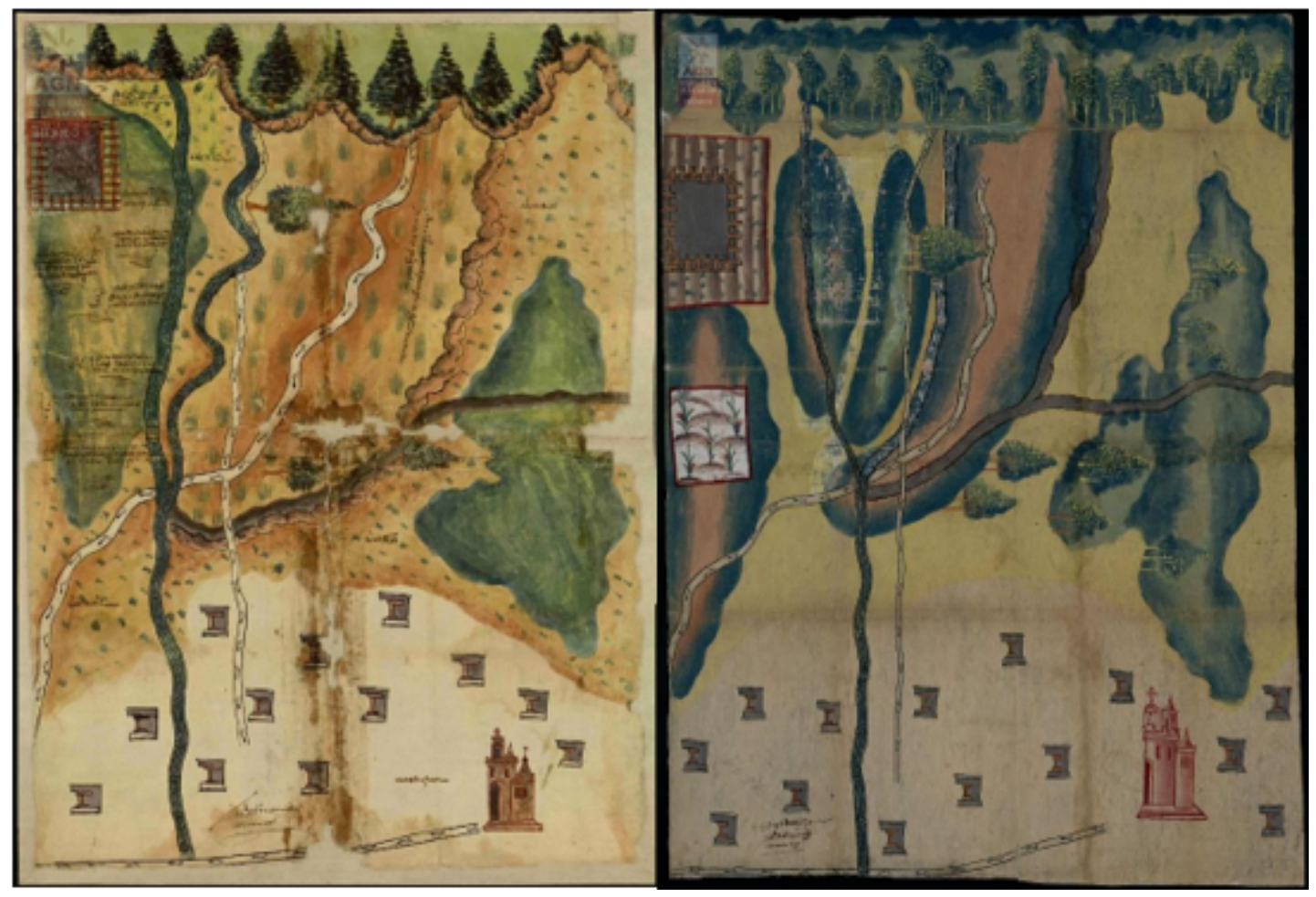

Fuente: imagen en dominio público.

A este respecto, en las páginas 160 a 163 de la "Relación del señorío de Xochimilco y de la república de indios de Chalco", incluida en el Corpus Cardona, se muestra la descripción del pueblo de Chicoloapan:

[p. 160] puebla de Chicualoapâ

Vexâdoacianorthe la puebla dha de Yztapalhoca por dicho camino Rreal de Tezcuco qes camino llano e poco torçido q a otro quarto de leua chica llegase a puebla de ŷdyos de Chicualoapâ.

[Se incluye el topónimo de Chicolopan que se localiza en el mapa de la relación de 1579]

Chicualoapâ

Vienello en nombre por esunas avecillas aquaticos q aq y en todo en laguna y mucho criase y q llaman Chicuatototl y dice su nome en castellano "En la fuête donde median las abeçillas

[costado izquierdo] Tiene la puebla sobre mil ŷdyos, qseran q nuestros niños q ablan la legua mexicana y cultiban maíz y trico para el ecomodors\% son ni espanos non beneficiado en el

[pág. 161] Côpyedha figura de su escudo de los papeles q mostraron yduos acianos q guardan de mûcho tiempo atrás y en ellos quêtan las ystorias

[Aparece una pictografía de una cabeza humana con el nombre de ApâztleChichimecotecutli]

Dicen ql prime fûdador del puebla lo fue ŷdyo de rraça Chichimeca llamada Apoztle príncipe qra del veçinoReyno de

Cuautinchan e aluego fueron III barrios del rreyno de Tezcuco. 
[costado izquierdo]

Asen quatrocientos y dos años de aqsta prima fudacion por el ŷdyoApâztle.

[Representación del Licêciado Pero Lopez, êcomêdero]

Algora se ecomieda de Pero Lopez, veçino de Mexico al q atributa\%

Muestraseaq a dho comedor e su subxecto]

En síntesis, esta descripción del Corpus Cardona presenta peculiares referencias, pues indica la fundación del pueblo en la época prehispánica, el nombre del primer gobernante Apâztle Chichimecatecuhtli, el cual estaba emparentado con la casa real de Coatlinchan y según informan al momento de escribir la relación habían pasado 402 años de su fundación. Para la época de la Monarquía española informan que era encomendero del pueblo el licenciado Pedro López, vecino de México, y habitaban mil indios en el pueblo (véanse figuras 9 y 10 ).

FIGURAS 9 Y 10

"Pueblo de Chicoloapan", de la "Relación de Xochimilco y de la república de Chalco", en Corpus Cardona.

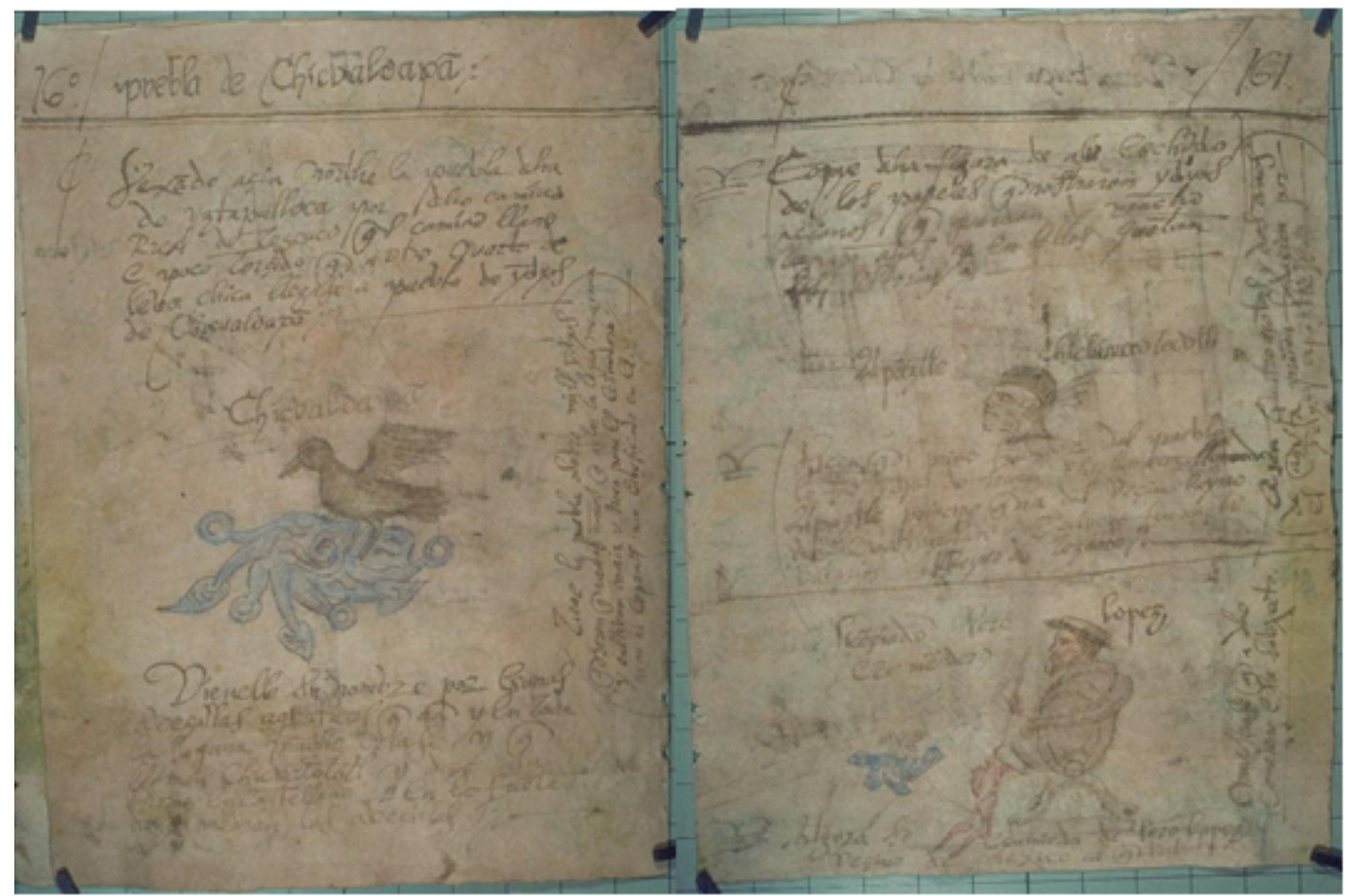

Fuente: reproducción autorizada por el doctor Andrés Reséndez.

Esta información parecería inusual, pero René Acuña refiere que Francisco del Paso y Troncoso (1905) publicó la transcripción de la "Relación de Coatepec y su partido", que incluía a los pueblos de Chimalhuacan y Chicoloapan. Tiempo después, George Kubler (1948) publicó los mapas de dichas relaciones. En la moderna transcripción de la "Relación de Chicoloapan" se lee lo siguiente:

La causa y razón por q[ue] se nombra Chicoaloapa [n], [según] dicen los viejos antiguos q[ue] hay al presente en este pueblo y sus sujetos, y ansí parece por sus pinturas antiguas q[ue] les dejaron sus pasados para su memoria, [es] q[ue], en el tiempo de la infidelidad de los naturales, que el primero fundador q[ue] fundó este pueblo con sus indios se decía Apaztli Chichimecatl: su origen, como parece por sus pinturas, se dice q[ue] fue de la parte y lugar que se dice Chicomeoztoc [...] [y] este cacique Apaztli, según parece por pinturas, fue descendiente y del tronco de los caciques y señores del pueblo de Coatlichan, q[ue] es de su M[a]j[esta]d; el cual, cuando llegó con su gente al sitio y asiento donde ahora están, halló una fuente de agua manantial, estancada alrededor, la cual tenían cercada y rodeada gran cantidad de pájaros pardos, del tamaño q[ue] son las codornices, $\mathrm{q}[\mathrm{ue}]$ tienen los pies, pecho y pico, amarillos, las coronillas de la cabeza, negras, y un poquito del pescuezo, y las pumas del rabo, blancas, q[ue] de contino estaban y bebían desta fuente, las cuales los indios, en su lengua, llaman chicuatototl. Y, por 
esta fuente y pájaros, tomó este pueblo, y le pusieron los antiguos, el nombre de Chicoaloapa[n]; y esta fuente parece hoy día junto al pueblo, aunq[ue] los naturales no beben della [...]. Y [dicen] que ha q[ue] está fundado este pueblo cuatrocientos y treinta años (Villacastín, 1986).

Debido a las semejanzas del texto, es muy probable que el Taller Cardona tuviese en los estantes de su biblioteca la obra de Francisco del Paso y Troncoso, así como las de Kubler (1948). Posiblemente, estas fuentes documentales le sirvieron de inspiración para confeccionar algunas partes del Corpus Cardona. Pero, lo que hace el autor intelectual del Taller Cardona es resumir la información histórica y en algunos casos cambiar nombres. Por ejemplo, con respecto a Chicoloapan en el Corpus Cardona se refiere que el encomendero era Pedro López y en la Relación de 1579 se mencionó a Gaspar López. Otros casos de comparativa entre ambos documentos se analizan en la tabla 1.

TABLA 1

Comparativa de información sobre Chicoloapan.

\begin{tabular}{|c|c|}
\hline Relación de 1579 & Corpus Cardona \\
\hline $\begin{array}{l}\text { cuando llegó con su gente al sitio y } \\
\text { asiento donde ahora están, halló } \\
\text { una fuente de agua manantial, } \\
\text { estancada alrededor, la cual tenían } \\
\text { cercada y rodeada gran cantidad } \\
\text { de pájaros pardos, del tamaño } \\
\text { q[ue] son las codornices, q[ue] } \\
\text { tienen los pies, pecho y pico, } \\
\text { amarillos, las coronillas de la } \\
\text { cabeza, negras, y un poquito del } \\
\text { pescuezo, y las pumas del rabo, } \\
\text { blancas, q[ue] de contino estaban } \\
\text { y bebian desta fuente, las cuales } \\
\text { los indios, en su lengua, llaman } \\
\text { chicuatototl. Y, por esta fuente y } \\
\text { pájaros, tomó este pueblo, y le } \\
\text { pusieron los antiguos, el nombre } \\
\text { de Chicoaloapa[n]; y esta fuente } \\
\text { parece hoy día junto al pueblo, } \\
\text { aunq[ue] los naturales no beben } \\
\text { della [...]. }\end{array}$ & $\begin{array}{l}\text { Vienello en nombre por esunas } \\
\text { avecillas aquaticos q aq y en todo } \\
\text { en laguna y mucho criase y q } \\
\text { llaman Chicuatototl y dice su nome } \\
\text { en castellano "En la fuête donde } \\
\text { median las abeçillas\% }\end{array}$ \\
\hline $\begin{array}{l}\text { y ansí parece por } \\
\text { sus pinturas antiguas q[ue] les } \\
\text { dejaron sus pasados para su } \\
\text { memoria, [es] q[ue], en el tiempo } \\
\text { de la infidelidad de los naturales }\end{array}$ & $\begin{array}{l}\text { Côpye dha figura de su escudo de } \\
\text { los papeles q mostraron yduos } \\
\text { acianos q guardan de mûcho } \\
\text { tiempo atrás y en ellos quêtan las } \\
\text { ystorias }\end{array}$ \\
\hline $\begin{array}{l}\text { [y] este cacique Apaztli, según } \\
\text { parece por pinturas, fue } \\
\text { descendiente y del tronco de los } \\
\text { caciques y señores del pueblo } \\
\text { de Coatlichan }\end{array}$ & $\begin{array}{l}\text { Dicen ql prime fûdador del puebla } \\
\text { lo fue ŷdyo de rraça Chichimeca } \\
\text { llamada Apoztle príncipe qra del } \\
\text { veçino Reyno de Cuautinchan e } \\
\text { aluego fueron Ill barrios del rreyno } \\
\text { de Tezcuco. }\end{array}$ \\
\hline $\begin{array}{l}\text { Y [dicen] que ha q[ue] está } \\
\text { fundado este pueblo cuatrocientos } \\
\text { y treinta años }\end{array}$ & $\begin{array}{l}\text { Asen quatrocientos y dos años de } \\
\text { aqsta prima fudacion por el ŷdyo } \\
\text { apâztle }\end{array}$ \\
\hline
\end{tabular}


Como puede verse en la tabla 1, el escribano del Corpus Cardona no copió tal cual el texto histórico, sino que resumió la información publicada por Francisco del Paso y Troncoso en 1905. Lo que resulta extraño es el empleo del término "ŷdyo de rraça Chichimeca", ya que la concepción de raza como grupo étnico no es común de esta época. Sobre este asunto se logra observar en textos de Fernando de Alva Ixtlilxóchitl, cronista tezcocano, la expresión "nación" chichimeca.

Aunado a esto, los autores del Corpus Cardona modificaron ciertos años, teniendo como objetivo plasmar fechas más antiguas. Por ejemplo, la relación de 1579 refiere que el pueblo de Chicoloapan se fundó hacía 430 años antes, es decir, en 1149; en cambio, el Corpus Cardona refiere que serían 402 años, si tomamos el año base de 1149 y le sumamos los 402 daría el año de 1551, fecha que trata de enmarcarse la obra. En una comparativa entre la información de la relación de 1579 y la que presenta la relación incluida en el Corpus Cardona se observan varias semejanzas.

Con respecto al análisis de la pintura o mapa depositado en el Archivo General de Indias, se logra observar que es una copia o "falsificación" la contenida en el Corpus Cardona. Esto se comprueba porque el mapa original de 1579 representa el centro del pueblo de Chicoloapan con tres construcciones virreinales: la principal se observa en el centro de la pintura y corresponde a la iglesia del pueblo (la que originalmente fue una capilla), la cual está constituida por una torre, el templo con techo a dos aguas y una construcción anexa. En cambio, en el Corpus Cardona se representa sólo el templo a dos aguas con su campanario y plasma la cruz atrial y dos capillas pozas en el centro de la plaza principal (véase Tabla 2).

TABLA 2

Comparativa iconográfica de la capilla principal de San Vicente Chicoloapan.

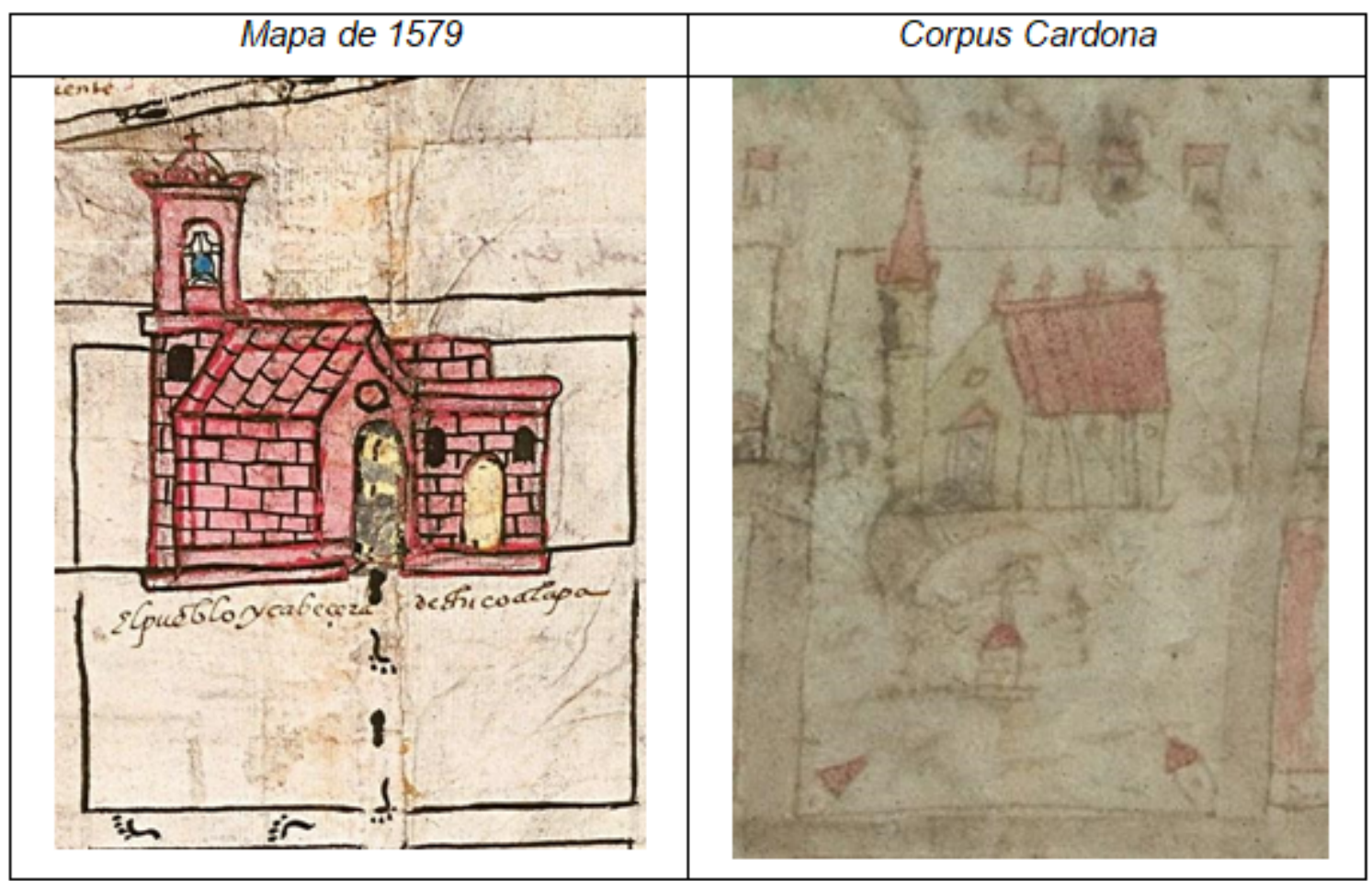

Fuente: reproducción autorizada por el doctor Andrés Reséndez.

En la parte superior izquierda se representa el templo de la "estancia de sacta maría"cuya construcción es sencilla, pues sólo se representó el templo y el campanario localizados en el camino que va Chalco. En el Corpus Cardona también se reprodujo esta edificaciónde forma simple, pues no usa colores y está sobre el "camino de Tezcuco para Chalco" (véase tabla 3). 
TABLA 3

Comparativa de elementos iconográficos de la estancia de Santa María.

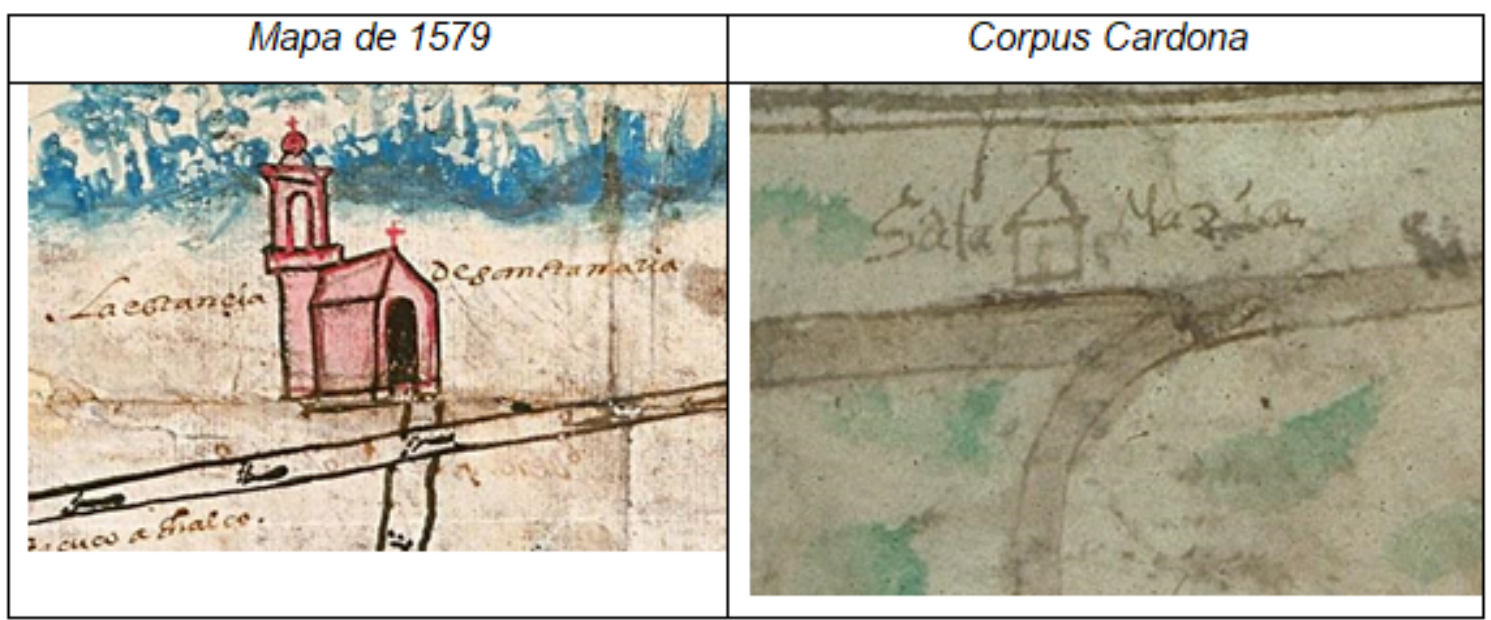

Fuente: reproducción autorizada por el doctor Andrés Reséndez.

La tercera construcción es la capilla de la "estancia de Coatongo" y se localiza entre dos caminos, uno de ellos iba de la Ciudad de México a Coatepec. En cambio, el mapa del Corpus Cardona sólo representa una capilla sin nombre y en una ubicación diferente. En esta sintonía, los caminos son casi exactos en ambos documentos, salvo los que van a Coatepec ya que el pintor del Cardona los omitió (Tabla 4).

TABLA 4

Comparativa de elementos iconográficos de la estancia de Coatongo.

\begin{tabular}{|c|c|c|}
\hline \multicolumn{2}{|c|}{ Mapa de 1579} & Corpus Cardona \\
\hline & & \\
\hline
\end{tabular}

Fuente: reproducción autorizada por el doctor Andrés Reséndez.

Con respecto a la traza del pueblo, se observa que estaba dividida en 14 manzanas, las dos más grandes eran: la de la iglesia de Chicoloapan y la plaza pública. En la parte inferior del mapa de 1579 se observa el agua, justamente la fuente que hace referencia la relación y al chichicuilote. En cambio, en el Corpus Cardona hay una variación, pues el pintor une las manzanas de la iglesia y la plaza principal como si fueran una sola. En este sentido, se debe recordar que la iglesia de Chicolopan era una pequeña capilla y no tenía un gran camposanto 
(García Pérez, 2020). Además en el Corpus Cardona en la parte inferior aparece la "fuente de Chicouapã", pero sin el topónimo del lugar (Tabla 5). Se debe de observar que en el Corpus Cardona se copió el topónimo de Chicoloapan en dos ocasiones y se refieren a él como "escudo" en distintas partes del texto (Tabla 6).

TABLA 5

Comparativa de elementos iconográficos de la fuente de Chicoloapan.

\begin{tabular}{|l|l|}
\hline Mapa de 1579 & Corpus Cardona \\
\hline &
\end{tabular}

Fuente: reproducción autorizada por el doctor Andrés Reséndez.

TABLA 6

Comparativa de los glifos de Chicoloapan.

\begin{tabular}{|l|l|}
\hline Mapa de 1579 & Corpus Cardona \\
\hline &
\end{tabular}

Fuente: reproducción autorizada por el doctor Andrés Reséndez.

Asimismo, el autor anexa detalles que no están en el mapa original. Por ejemplo, en la parte superior de la traza del pueblo se plasmaron 11 casas, tal vez de indios y en todas las manzanas se hizo algo similar, es decir de forma horizontal se dibujaron las entradas de las casas, y en vertical los techos rojos. Esta característica es muy común en los planos de la Ciudad de México del siglo XVIII, pero inusual en la cartografía del siglo XVI.

\section{CONSIDERACIONES FINALES}

Como puede verse en este primer acercamiento, el Corpus Cardona está compuesto por al menos cinco relaciones geográficas del sur de la Ciudad de México. Para este trabajo sólo me referí a dos relaciones geográficas incluidas en el corpus: la de México y la de la región de Xochimilco y Chalco, mientras que en 
otro texto realizo una propuesta clara para mostrar la estructura y la forma de las relaciones incluidas en el Cardona. Dicho lo anterior, hasta el momento se desconoce la existencia de las relaciones originales del siglo XVI de estas dos regiones.

Debido a que se consideran perdidas las cinco relaciones que están incluidas en el Corpus Cardona, es posible asumir que los autores vieron un vacío en la historiografía y supieron aprovecharlo al recrear y copiar códices y documentos. Es decir, reconstruyen la historia de la región con elementos de escritura indígena, contenida en otros códices, y conforman un tercero que hacen pasar por original, además de realizar réplicas de mapas del siglo XVI.

En este sentido, en el presente análisis de tres páginas sobre Chicoloapan que están incluidas en la "Relación del señorío de Xochimilco y de la república de indios de Chalco", que forma parte del Corpus Cardona, se puede observar que el Taller Cardona reutilizó una fuente histórica poco conocida y modificó los datos para darle un rasgo más antiguo, pero respetó en gran medida los datos duros de la fundación del pueblo. Es posible que, así como este ejemplo haya más en todo el corpus.

\section{Agradecimientos}

Esta investigación se presentó como trabajo final para el seminario que impartieron los doctores Renato González Merlo y Dafne Cruz Porchini en El Colegio de México, por lo cual agradezco sus comentarios que enriquecieron y pulieron el texto. Del mismo modo a las doctoras Linda Arnold, Ana Rita Valero de García Lazcuráin y Stephanie Wood por obsequiarme imágenes del Corpus Cardona y poner en mis manos algunas hojas de este documento. Del mismo modo, al doctor Andrés Reséndez por darme la autorización para publicar las imágenes que él y Bauer digitalizaron del Corpus Cardona. Por último, al doctor Alfredo Peñuelas Rivas por las sugerencias en la redacción.

\section{REFERENCIAS}

Batalla Rosado, J. J. (2002a). El Códice Tudela y el Grupo Magliabechiano: la tradición medieval europea de copia de códices en América. Madrid: Ministerio de Educación Cultura y Deportes, Agencia Española de Cooperación Internacional, Testimonio Compañía Editorial.

Batalla Rosado, J. J. (2002b). Códice Tributos de Coyoacán. Madrid. COMMA.

Batalla Rosado, J. J. y González Centeno, G. (2017). La falsificación de códices mesoamericanos: una revisión de su censo. En I. Álvarez Cuartero (ed.), Conflicto, negociación y resistencia en las Américas (pp. 17-30). Salamanca: Universidad de Salamanca.

Batalla Rosado, J. J. y González Centeno, G. (2019). Genaro López: de pintor contratado por el gobierno mexicano a falsificador de códices. En A. Martínez Riaza y M. Luque Talaván (eds.), América: problemas y posibilidades (pp. 101-119). Madrid: Ediciones Complutense.

Bauer, A. J. (2009). The search for the Codex Cardona on the trail of a sixteenth-century Mexican treasure. Durham, London: Duke University Press.

Boehm, G. (2011). ¿Más allá del lenguaje? Apuntes sobre la lógica de las imágenes. En A. García Varas (ed.). Filosofía de la imagen (pp. 87-106). Salamanca: Ediciones de la Universidad de Salamanca.

Brito Guadarrama, B. (2006). Un manuscrito de Francisco del Paso y Troncoso sobre el Códice Ciclográfico. Estudios de cultura nábuatl, 37, 275-291.

Colston, S. A. (1985). An Examination of the Codex Cardona. Inédito.

García Pérez, V. E. (2020). La parroquia de San Vicente a través del tiempo. En A. Contla Carmona, C. García Santillán y G. Hernández Velázquez (coords.). Crónicas de Texcoco 6 (pp. 93-108). Texcoco: Consejo de la Crónica Municipal de Texcoco.

Glass, J. B. (1964). Catálogo de la colección de códices. México: INAH. 
Glass, J. B. (1975). A catalog of falsified Middle American pictorial manuscripts. En H. F. Cline (ed.), Handbook of Middle American Indians (vol. 14, pp. 297-310). Austin: University of Texas Press.

González Centeno, G. (2018). Falsificaciones de códices en papel de fibra de coco. En J. J. Batalla Rosado, J. L. de Rojas y L. Pérez Lugones (coords.). Códices y cultura indígena en México. Homenaje a Alfonso Lacadena García Gallo (pp. 411-438). Madrid: Distinta Tinta.

Kingsborough, E. K. (1830-1848) Antiquities of Mexico: comprising facsimiles of ancient Mexican paintings and hieroglyphics... together with the monuments of New Spain, by M. Dupaix... the drawings on stone by A. Aglio. London: Robert Havell, Colnaghi Son and Co. [vols. I-VII] y Henry G. Bohn [vols. VIII-IX].

Kubler, G. (1948). Mexican Architecture of the Sixteenth Century. New Haven: Yale University Press.

Meer, R. V. (2010). The History of a Falsified Mesoamerican Pictorial Manuscript: The Codex Moguntiacus. Indiana. 27, 193-229.

Muñoz Camargo, D. (1981). Descripción de la ciudad y provincia de Tlaxcala de las Indias y del mar océano para el buen gobierno y ennoblecimiento dellas. Edición facsimilar del Manuscrito Glasgow con un estudio preliminar de René Acuña. México: Universidad Nacional Autónoma de México.

Paso y Troncoso, F. del. (1905). Papeles de la Nueva España 5. Madrid: Establecimiento tip. "Sucesores de Rivadeneyra".

Pomar, J. B. (1986), “Relación de Tezcoco”. En R. Acuña (ed.). Relaciones geográficas de la Nueva España siglo XVI: México. (Tomo tercero). México: Universidad Nacional Autónoma de México.

Pulido Rull, A. (2020). Mapping Indigenous Land. NativeLand Grants in Colonial New Spain. Norman: University of Oklahoma Press.

Ramírez López, J. E. (2021). El denominado "Códice Cardona": un corpus inusual de "realaciones geográficas" del Valle de México. En J. J. Batalla Rosado, L. Prez Lugones y Ma Rúiz Barrios (coords.), La expresión de la cultura indigena en los códices del centro de México, (pp. 303-332). Varsovia: Instituto de Estudios Ibéricos e Iberoamericano / Universidad de Varsovia

Roque, G. (2012). Visual Argumentation. A Reappraisal. En F. H. Van Eemeren y B. Garssen(eds.). Topical Themes in Argumentation Theory: Twenty Exploratory Studies (pp. 273-288). Dordrecht: Springer Netherlands.

Villacastín F. (1986). Relación de Coatepec y su partido. En R. Acuña (ed.). Relaciones geográficas del siglo XVI: México (pp. 169-174). México: UNAM-IIA.

Wood, S. (2010). Reseña de Arnold J. Bauer, The search for the Codex Cardona on the trail of a sixteenth-Century Mexican treasure. Durham, London: Duke University Press, 2009. A contra corriente, 7(3), 389-401.

\section{Notas}

1 https://www.ansorena.com/lotes/2020/10/20-0?destination=/subastas/actual.

2 http://www.siempre.mx/2017/04/zocalo-al-servicio-de-las-ocurrencias/ 